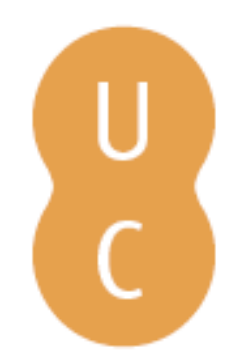

\title{
pommalina
}

\section{La Odisea de César Brie: Ulises en tiempos de la globalización}

\author{
Autor(es): $\quad$ Atienza, Alicia María
}

Publicado por: Centro de Estudos Clássicos e Humanísticos da Universidade de

URL

persistente: URI:http://hdl.handle.net/10316.2/30168

DOI: $\quad$ DOI:http://dx.doi.org/10.14195/978-989-721-038-9_5

Accessed : $\quad$ 26-Apr-2023 14:15:22

A navegação consulta e descarregamento dos títulos inseridos nas Bibliotecas Digitais UC Digitalis, UC Pombalina e UC Impactum, pressupõem a aceitação plena e sem reservas dos Termos e Condições de Uso destas Bibliotecas Digitais, disponíveis em https://digitalis.uc.pt/pt-pt/termos.

Conforme exposto nos referidos Termos e Condições de Uso, o descarregamento de títulos de acesso restrito requer uma licença válida de autorização devendo o utilizador aceder ao(s) documento(s) a partir de um endereço de IP da instituição detentora da supramencionada licença.

Ao utilizador é apenas permitido o descarregamento para uso pessoal, pelo que o emprego do(s) título(s) descarregado(s) para outro fim, designadamente comercial, carece de autorização do respetivo autor ou editor da obra.

Na medida em que todas as obras da UC Digitalis se encontram protegidas pelo Código do Direito de Autor e Direitos Conexos e demais legislação aplicável, toda a cópia, parcial ou total, deste documento, nos casos em que é legalmente admitida, deverá conter ou fazer-se acompanhar por este aviso.

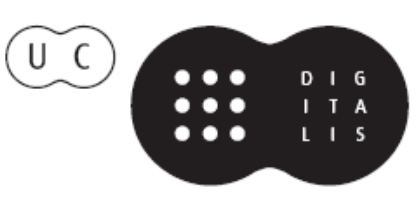




\section{De ayer a hoy}

\section{Influencias clásicas en la literatura}

\section{Aurora López, Andrés Pociña, Maria de Fátima Silva (coords.)}




\title{
LA Odisea de César Brie: Ulises en Tiempos de la Globalización
}

\author{
Alicia María Atienza \\ Universidad Nacional de la Patagonia Austral
}

Desde una relación de traspase entre teatro y ritual, la propuesta de Brie trata de unir experimentación y tradición, y utiliza como recurso el grotesco, la yuxtaposición despiadada de lo trágico y lo humorístico, del pasado con el presente. En una propuesta escénica profundamente intercultural la matriz mística se entreteje con voces, músicas y danzas americanas, en un texto híbrido que restituye el núcleo metafórico de los antiguos mitos y los reviste de una dignificación comprometida y actual.

Fatal accidente en Flores. Mueren dos personas y un boliviano.

Crónica

La adaptación teatral de relatos míticos griegos ocupa un importante espacio en la obra de César Brie ${ }^{1}$, dramaturgo, actor y director argentino, radicado en Bolivia, fundador del Teatro de los Andes en Yotala, cerca de Sucre $^{2}$. Brie comparte con E. Barba (director del Odin Theatre donde trabajó varios años) la creencia en que:

Muchos símbolos están carcomidos, y en la boardilla del siglo XX yacen bolsas y bolsas de esperanzas marchitas. Con los mitos no sucede lo mismo. Los mitos son sombras indelebles. Se han ido del gran mundo de una vez y para siempre pero nutren los pequeños mundos. Vivimos en dos mundos. El Pequeño mundo es el ambiente en el cual nos movemos, la trama de nuestras relaciones, el paisaje que nos pertenece y que podemos adaptar a nuestras necesidades (Barba, 2005: 70).

Con ese sentido, Brie vuelve a textos antecedentes de la cultura occidental, los poemas homéricos ${ }^{3}$ y el drama satírico homónimo de Eurípides, para

${ }^{1}$ César Brie nació en Argentina, exiliado en Europa durante la dictadura de Videla, trabajó junto al Odin Theatre de Dinamarca durante nueve años y se formó con Iben Nagel Rasmussen. A principios de los '90 se establece en Bolivia, compró una finca en Yotala y fundó el Teatro de Los Andes, compañía que se convirtió en un paradigma de las artes escénicas en Bolivia y llevó al teatro boliviano al ámbito internacional. Brie, C. (2009) "El arte cambia por dentro a las personas”, http://www.artezblai.com/artezblai/cesar-brie-el-arte-cambia-por-dentro-a-laspersonas.html (Consulta: 11-04-2011)

${ }^{2}$ Resulta significativo señalar que cuando regresa a América Brie busca instalarse "en un país latino que valiera la pena por su cultura. Por eso Bolivia".

$\underline{3}$ La elección de los textos antiguos es de por síllamativa, e implica un cruce no sólo de siglos 
reescribir tres piezas de tema griego: la Ilíada, la Odisea y El Cíclope, quizá como alusión indirecta a las trilogías trágicas del teatro clásico. Brie (2005: 49) defiende el valor de reapropiarse de los textos griegos desde un país latinoamericano como Bolivia cuando explica:

Ciertas ceremonias y rituales del mundo griego antiguo se me presentaban como acciones que en Bolivia se practican hoy día. Usé esta constatación, en modo algo terrorista, para callar la boca a los ignorantes y nacionalistas de siempre que ponían a priori mala cara, dudando que tuviera sentido y legitimidad proponer un clásico griego en la Bolivia contemporánea.

Desde una relación de traspase entre teatro y ritual la reescritura de Brie traduce la Ilíada en una advertencia sobre "el regreso de la violencia" en América Latina y la Odisea en un relato sobre la problemática de la migración, donde Ulises encarna la figura de los migrantes latinoamericanos que intentan ingresar y vivir en los Estados Unidos.

Nos ocuparemos aquí de la versión teatral de la Odisea, de César Brie, para reflexionar sobre las transformaciones del texto fuente en dos aspectos centrales: el cambio de género, de texto narrativo a dramático y el pasaje intercultural de la cultura griega arcaica al ámbito latinoamericano actual. En primer lugar analizaremos algunos de los procedimientos de la adaptación intergenérica por los cuales el texto origen cambia su estatuto inicial y pasa a participar de un tipo de texto diferente, la adaptación teatral, uno de los géneros centrales para el intercambio internacional en que se plantea la problemática del comparatismo (Cilento, 2000: 9). En segundo lugar consideraremos la

sino de género. De la cultura griega a Bolivia, de la narración heroica a la escena. En lugar de las habitualmente revisitadas obras de teatro clásico, Brie elige las fuentes primarias y proteicas que fueron también en su época fuente para los dramaturgos griegos. En referencia a las crisis en la historia del grupo y a la puesta en escena de La Odisea, comenta Pablo Ortiz: "Como si se tratase de un castigo de los dioses del Olimpo, esta crisis duró exactamente el tiempo en que no presentaron obras de Homero, desde la última presentación de La Ilíada, hasta el comienzo del trabajo para la adaptación de La Odisea. Ahora Ithaca es Yotala y la hacienda que cobija al grupo, un castillo desde el que intentan reinventarse." Ortiz, P. (2008) "Todos somos Ulises en La Odisea", http://www.eldeber.com.bo/brujula/2008-11-22/nota.php?id=081121222833 (consulta 11-2-2011)

4 "La Odisea" ofreció 44 funciones en una gira por Italia, se estrenó por primera vez en España el 10-10-2009 en el IX Festival Iberoamericano de Teatro Contemporáneo de Almagro, y luego participó del festival de Cádiz. El tema del IX Festival giró en torno a la relación 'Teatro y Compromiso', y el núcleo monográfico lo constituyeron los montajes del Teatro de los Andes. Fue posible compartir la historia y las técnicas de esta compañía a través de un taller y el grupo recibió además el Premio Gallo de la Veleta, que otorga el Festival. http:// www.artezblai.com/artezblai/teatro-de-los-andes-recibe-el-premio-gallo-de-la-veleta-enel-ix-festival-iberoamericano-de-teatro-contemporaneo-de-almagro.html (11 octubre 2009) (Consulta: 23-03-2011) 
transformación poética del texto en cuanto adaptación intercultural, en el cruce Occidente/comunidades latinoamericanas, tipo de adaptación que como expresa Dubatti (2008: 161) "marca el encuentro de visiones del mundo y concepciones estéticas muy distintas y distantes, de allí su especial fascinación en la fundación de terceras territorialidades".

\section{Del relato a la acción: la transformación genérica}

Teatro es lo que ocurre. Jorge Eines

La adaptación genérica implica la trasposición del texto de un modo representativo a otro (narrativo/dramático) por medio de una serie de operaciones textuales, entre ellas, alteraciones en la temporalidad, variaciones en la velocidad y frecuencia en el relato de los hechos, reelaboración de la instancia narrativa. ${ }^{5}$ La reescritura de Brie resuelve con eficacia un doble desafío: por un lado, trasponer la historia épica en una extensión viable para la escena y, por otro, traducir a un discurso actual y latinoamericano el verso épico griego, sin que la reescritura pierda en profundidad y poder de significación. ${ }^{6}$ Conserva el título, Odisea que declara desde el inicio el vínculo con el texto fuente, condición insoslayable de la adaptación en tanto género específico

${ }^{5} \mathrm{E} 1$ Coro, los prólogos e incluso los relatos de mensajero que cuentan o recitan la acción en vez de representarla son algunos de los tantos remanentes de lo épico presentes en la forma dramática clásica que la reescritura de Brie conserva, no de manera formal sino a nivel funcional. La música en vivo está a cargo de los nueve integrantes del elenco que tocan distintos instrumentos cuando no le toca actuar. Guitarra, violín, chelo, tambor, clarinete y charango intervienen en las partituras creadas por el músico Pablo Brie. (Arias, 2010)

${ }^{6} \mathrm{El}$ parlamento de los personajes es en verso, a lo que se suma los actores músicos que están siempre en escena, los cantos y la coreografía coral de los grupos, elementos que exhiben la relación de dependencia con el modelo clásico (el canto épico y el coro teatral). Las intervenciones grupales están concebidas de manera semejante al coro en el teatro griego, con canto, coreografía y musicalización Al final de la primera escena, especie de prólogo, la didascalia indica la párodos o entrada del Coro: "Entran los actores y se ponen los zapatos. Cantan"1.1. Lo mismo el canto de las esclavas (1.3), la canción del aeda Femio, en las escenas del primer acto (1.5.3). Las mujeres de Circe bailan al son de los tambores (2.1). En el acto dos un Leitmotiv acompaña el primer sueño de Ulises en su patria, y el reconocimiento entre Ulises y Telémaco y el abrazo entre Telémaco y su madre (2.5, 6 y 7). El canto y la música disimulan el estruendo de la masacre de los pretendientes en la última escena: "A ver, cantame, Yotaleña... No esa otra, viva mi patria. A ver...Desde lejos... Y ese huaynito... Eso seguí..." le dice Ulises a Femio, y las didascalias indican "Popurri de canciones que no acaban" (2.13.1). Cantan mientras las esclavas sacan los cuerpos y limpian. Luego forman en fila. Femio entona un punteado que acompañará el texto de Melanto (2.13.2). Durante el viaje de bailan kullawada y potolos, danzas bolivianas de tradición prehispánica, ya que el grupo trabaja con las fuentes culturales andinas que se expresan a través de la propia música, fiestas y rituales. En la escena final de la guerra civil suenan los tambores, golpean con trapos, gritan al unísono (2.13.5). 
(Dubatti, 2010, 154-5). El reconocimiento de la precedencia textual y el homenaje al autor como referente de autoridad son explicitadas por el coro:

El viaje, la ausencia, el destino, la furia/ la angustia, el regreso, el naufragio, el dolor./ Esta vieja historia la contaba un ciego./ ¿Cuándo comenzó? ¿Quién partió primero?/ ¿Para qué se fueron, quién los expulsó? (1.4)

La estructura dramática tiene dos actos, organizados a su vez en escenas, once en el primero y 13 en el segundo, número análogo a los 24 cantos de la Odisea homérica. La secuencia reformula sin transformaciones radicales los núcleos de la historia odiseica: la Telemaquia, las aventuras de Odiseo, el regreso, la venganza sobre los pretendientes. Sin embargo, una primera mirada al índice muestra ya una serie de modificaciones significativas, especialmente en el itinerario del viaje de Ulises, que se desdobla en el viaje de ida del primer acto, y en el regreso del segundo acto. Desde los títulos se marca la trasposición de Europa al territorio americano y el viaje de Ulises por el Mediterráneo a la migración actual de miles de latinoamericanos a USA. Así leemos "México", "La frontera", "El desierto", "Minuteman”, "E1 destino de los emigrantes", "La deportación". Por otro lado, el título de la última escena "Guerra civil" pone nombre a la inversión del desenlace, sobre la cual volveremos.

Brie reelabora la instancia narrativa, "una de las principales opciones estructurales para el adaptador" (Cilento, 2000: 22) relacionada con la desaparición del narrador épico, heterodiegético y externo. ${ }^{7}$ Distribuye el elemento narrativo en los parlamentos de los personajes lo que implica también la construcción y distribución de variados puntos de vista sobre los acontecimientos. Las palabras vivientes en el presente de la escena, operan la trasmutación del pasado en presente y del mundo griego al contexto actual de Latinoamérica y del mundo globalizado.

Telémaco visita al viejo Néstor ${ }^{8}$ para tener noticias de su padre, pero en vez de encontrarlo en la playa dirigiendo el sacrificio a Poseidón en el seno

${ }^{7}$ Identidad del narrador según conceptos de G. Genette (1989). El poema homérico favorece la operación por su reconocido carácter teatral en sentido amplio, ya que más de la mitad del texto está contada por el discurso directo de los personajes (el relato autobiográfico de Odiseo en el país de los feacios es el más extenso y ocupa cuatro de los veinticuatro cantos).

${ }^{8}$ Néstor pertenece al bando vencedor pero lejos de repetir el discurso triunfalista presenta la guerra a través de la pérdida de su hijo Antíloco, apenas aludida por el texto de origen: Lo llevé a las naves. Sus ojos abiertos/ya no me miraban, su boca no hablaba,/sólo perdía sangre./"Hijo, soy tu padre, aunque seas un hombre,/aunque tengas hijos/sigues siendo un niño dentro de mí./ Regresa te ruego,/vuélvete pequeño./No sabes hablar, por eso te callas,/ llora solamente, sólo tienes hambre,/ sólo tienes sueño, estás en mis brazos/ ponte a descansar. Regresa hijo mío,/ la muerte no existe, es sólo un mal sueño."/ Así le decía mientras lo cargaba,/ su cuerpo ya tieso, frío entre mis brazos,/ su alma hecha viento ya nada decía. Pero me vengué...(1.7.2) 
de una comunidad armónica, lo encuentra en un hospital, entre los lisiados y heridos de la posguerra de Troya, símbolo metonímico de todas las guerras:

Entré a los quirófanos, busqué en los repartos. Los niños de Troya, de Bosnia, de Irak, de Rwanda, Vietnam, los que se salvaron luego del incendio allí se encontraban. Los rostros quemados, llagas de napalm. Otros habían creído que llovían del cielo uvas de metal y allí estaban, ciegos, sin brazos, sin piernas. Habían jugado con frutos prohibidos de dioses siniestros. Lo encontré a Néstor, en silla de ruedas, su mano temblaba, los ojos perdidos miraban afuera, los muertos quemados, la hoguera y el humo, el jardín, las casas, la línea del mar. $(1.7 .2)$

En el pasaje intergenérico la diosa Atenea sigue siendo un personaje con funciones actanciales propias (impulsa el regreso de Ulises, fortalece a Telémaco, consuela a Penélope, protege a Ulises y su familia), pero asume también la voz de un testigo con efecto de distanciamiento, sin que se pueda homologar con el presentador del teatro épico brechtiano completamente separado de la acción dramática. Relata episodios del texto fuente relegados al espacio extraescénico, realiza una síntesis reductiva de pasajes importantes, y con frecuencia expresa la función valorativa frecuente en la voz del narrador homérico. Así plantea la situación de la nostálgica Penélope haciéndola extensiva a todas las mujeres e hijos de inmigrantes que sufren abandono y acoso, mientras esperan en vano a los maridos y padres ausentes:

Penélope esposa, tu cama vacía son cientos de camas/ tu hijo pequeño no es único hijo./ Edificios llenos de niños sin padres,/ casas acosadas por los pretendientes./ por deudas, parientes, por falsos amigos./ Penélope, un nombre y miles los rostros/ que esperan, que miran la nave que nunca/ traerá de regreso a sus seres queridos. (1.5.5)

El salto de género de la épica al drama supone una metábasis állo génos y exige una síntesis reductiva rigurosa ${ }^{9}$. Brie desecha numerosos materiales del texto homérico y enfatiza algunos aspectos y acontecimientos que el poema griego, dirigido a la exaltación del orden heroico, sólo roza o presenta de manera tangencial. Por ejemplo, desarrolla in extenso la relación del héroe con Calipso, que Homero trata con la discreción propia de la épica. Incorpora a

\footnotetext{
${ }^{9}$ A nivel de la historia se respeta en líneas generales el hipotexto, pero las operaciones de compresión y expansión de las escenas (algunas en un solo episodio y otras desarrolladas en varias microescenas) introducen la variación. Las reflexiones de Brie (2000: 9) sobre la Ilíada, son aplicables a la Odisea también: "Me angustia la duración de la obra. Tendría material para seis horas pero decido no superar los dos actos y tratar de no sobrepasar las tres horas. Terminan siendo dos actos con una duración de dos horas y 25 minutos en total”.
} 
la diosa Afrodita, ausente del texto homérico, para marcar la resignificación del episodio focalizado ahora ya no sobre el triunfo de la philía familiar sino sobre las aventuras eróticas del personaje. La relación entre Ulises y Calipso se invierte ya que es ella la que expresa el deseo de sentirse mortal. En una escena cargada de violencia y erotismo, donde lo corporal adquiere preeminencia, los amantes luchan cuerpo a cuerpo y Calipso atisba por primera vez la experiencia de la mortalidad:

Bajo el sol de la mañana por primera vez pienso en el tiempo y en el tiempo que habrá sin él. De veras soy nueva para esto y quisiera ser humana y mortal como él. Porque justo esto yo no lo conozco. No conocía esperar encontrar hallar. No conocía. Y no conozco perder. ¿Qué es lo que queda de lo que fue? (Esc. 6)

Otra de las transformaciones textuales, central para la concepción poético ideológica de la obra es la reiteración en tono ritual del relato de la masacre de los pretendientes, las esclavas y los sirvientes, con sórdidos detalles y los tonos más crueles:

Mi padre va a regresar./ A todos los pretendientes les cortará la cabeza./ Verán cómo va a quedar el patio de casa lleno / de tripas, brazos cortados, ojos, lenguas, / y en la sangre me voy a lavar la cara./Y también a las esclavas que con ellos se acostaron/ las vamos a exterminar. Las ahorcaremos en el patio / todas juntas a una cuerda. Recogeré la mierda / que chorreará de sus piernas para abonar nuestra huerta/ Y a los siervos, los traidores, les cortaremos la lengua,/ los castraremos después, luego los mutilaremos/ y el tronco lo arrojaremos a los cerdos/ que los coman mientras lloran y suplican./ Muéranse hijos de puta, mueran todos de una vez. (1.8.6)

Este pasaje se convierte en un leitmotiv que todos los actores de cara al público gritan al final de la obra en un estallido de violencia física y verbal.

De la cultura griega arcaica al presente latinoamericano: el largo viaje intercultural de la Odisea

Itaca se parece mucho a Bolivia.

C. Brie

Brie diseña la primera escena a manera de prólogo donde se presenta al personaje principal y se plantea la poética teatral de la adaptación en el plano temático y transvalorativo. Los dioses, como en la Odisea homérica, están reunidos, no en el Olimpo sino en una playa con reposeras, anteojos de sol y cigarrillos, atributos placenteros de la modernidad global. Zeus colecciona con 
displicencia, como quien junta caracoles en la arena, zapatos que la marejada acerca a la costa, restos macabros de los que mueren en el mar. Atenea reconoce un zapato y dice: "Yo conozco al dueño. / Ulises se llama, hace mucho tiempo/ que se fue a la guerra y nunca volvió./ Lo atrapa una diosa de una isla lejana."(1.1) Las comunicaciones globales ponen en contacto los extremos del planeta y conectan el plano humano con el plano divino. Hermes responde un llamado de Ulises a su celular:

Aló, sí ¿Ulises? ¿Ulises Choque?/ ¿Estás en España, en el aeropuerto?/ ¿Barajas se llama? ¿Qué problemita?/ ¿El de migraciones, un tal Polifemo?/ ¿Te falta la visa, quieren deportarte, no te hacen pasar? (1.1)

Enseguida Afrodita recibe otro llamado:

¿Aló, Ulises Quispe? ¿No estás en Ushuaia? / ¿En Londres... México... en el Paso? / No escucho... Hay ladridos ¿Los perros guardianes de la policía de Escila y Caribdis? (1.2)

El mestizaje del nombre griego con los apellidos peruanos, Choque o Quispe, resemantiza el estatuto del personaje aproximándolo al de un rol tipificado, el de cualquier inmigrante. Su identidad se vuelve plural y ubicua, inscripta en una geografía donde los espacios se multiplican. Ulises es cualquier migrante y puede estar en España, Ushuaia, Londres, México, o El Paso, lugares definidos como ámbitos de riesgo, fronterizos y señalados como no lugares por las palabras "aeropuerto", "migraciones", "visa", "deportar".

Coherentes con el cambio de contexto, los célebres monstruos homéricos sufren también una metamorfosis: en el aeropuerto de Barajas Polifemo es el empleado de migraciones que lo de-porta dejándolo afuera del mundo deseado del bienestar; Escila y Caribdis son los perros de la policía de frontera en México. Por su naturaleza polimórfica propia de lo monstruoso, Caribdis encarna luego los peligros del golfo de México, y Polifemo el jefe de la mara Salvatrucha que opera en la frontera mexicana:

Polifemo Blacky, jefe de la mara de La Salva Trucha.. Tres veces al fresco allá en California: vendía cocaína, me pude escapar. Mara Salvatrucha. Mi himno y mi lema: Quiero vida loca, sexo, plata y droga....Controlamos trenes, robamos, asaltamos. Si hallamos mujeres, el peaje es violarlas. (2.11.3)

Es durante el viaje de Ulises donde se produce más profundamente la resemantización de los personajes y del espacio geográfico y cultural. Ulises, como en el texto original, cuenta el viaje en primera persona, como protagonista de los hechos. Comienza su relato diciendo: "Yo partí de Troya, o sea Bolivia". 
En un juego especular el espacio troyano, punto de regreso, se hace uno con la tierra patria, Bolivia, la dirección del viaje se hace reversible, la ida y la vuelta se funden y se desdibujan las coordenadas geográficas. En un itinerario que atraviesa Perú, Ecuador, Colombia y Guatemala, las etapas del viaje odiseico se homologan, con desviaciones pero siempre reconocibles, a los episodios de la migración de latinoamericanos a USA.

Del otro lado de la frontera, los males no terminan, se interpone Escila (el desierto de Arizona, los perros de la policía de frontera, el coyote o pollero cruza a los ilegales por el desierto), los grupos parapoliciales, "los voluntarios del Minuteman" que "defienden su patria de los miserables". Hasta que, superadas la últimas pruebas los emigrantes se dispersan a sus diferentes destinos: Chicago, Houston, Miami, Monterrey, la Itaca, no griega sino de N. York, destino de Ulises. Una terror terminó pero una nueva pesadilla comienza en la última escena del primer acto, es la verdad del sueño americano:

Lo tuyo es vivir escondido siempre,/ trabajando duro por buena moneda./ Aprender inglés./TODOS: Yes sir, I can do,/ULISES: Hacer los trabajos que los demás gringos no quieren hacer. (1.9)

El viaje heroico no conduce a la conquista del nuevo territorio sino al fracaso y a la infelicidad, a la pérdida del nombre, de la identidad, de la propia historia desgajada de la comunidad de origen: "Nadie te llamabas, ahora eres Ulises, Ulises Mamani, Ulises Morales..."

En clave paródica, los Estados Unidos son el reino de Circe, cuya poción mágica es la coca cola, allí se impone el abandono de la lengua, la comida chatarra para los hambrientos y la diversión obscena para los solitarios:

Pasen, adelante, pobres extranjeros,/ Venían de lejos, estaban con hambre/ Hamburguesas hot dogs, chizines papitas./ ¿Sajta, fricasé, feijoada tal vez?/ Comida chatarra. Todo lo que quieran./ Coman mis cerditos, hasta hartarse bien./ ...En la isla de Circe nadie va a llorar.../ ¿Para qué acordarse? No van a volver.../

-..ंYa no hablan su lengua? (2.1)

El destino de los ilegales está permanentemente amenazado por la deportación, que reelabora el episodio de los Feacios en la figura por funcionarias insensibles y vulgares (el coro). Los hombres declaran su nombre y nacionalidad: Ulises Quispe, Ulises Laertida, Ulises Ramaciotti, Ulises 
Achirico $^{10}$, de Bolivia, Argentina, Uruguay, Perú ${ }^{11}$. Ninguno de ellos tiene visa, son "turistas", su proveniencia es Itaca, Itaca su destino también ${ }^{12}$.

La llegada de regreso a Itaca/Bolivia implica la humillación más dolorosa, la de los compatriotas que no lo reconocen como tal ${ }^{13}$. Ulises no retorna a la Itaca que dejó, ni es el mismo que era al partir. La profecía de Tiresias se cumple y describe una sociedad que ha quedado desgarrada, signada por la injusticia y el rencor, preñada de odio y violencia:

La Itaca que dejaste ya no existe más./ Tu casa invadida por hombres voraces,/ que asedian tu esposa y asaltan tus bienes./ Tu tierra en desorden, sin ley, llena de odio./ Verás a los hijos golpear a sus padres./ Oirás en las plazas a los demagogos provocar desorden, llamar a venganza./ Fuera, en las montañas, verás que el silencio de los campesinos/ afila guadañas, sostiene el arado con fuerza excesiva. Deberás elegir y no será fácil/ entre sumisión o fuerza, lo legal, lo justo, entre el silencio y la furia, entre el dolor y el desgarro./ Verás separarse calma y dignidad, verás la justicia contraerse en el odio.(2.2)

\section{La peregrinación del nombre: Ulises Quispe, Polifemo Blacky}

La Odisea de Brie hace de Ulises un colectivo donde habitan los migrantes de todos los pueblos arrasados del planeta; Troya es Guatemala, Bolivia, Palestina, Irán, Afganistán, Libia, cualquiera de los países asolados por la guerra, el hambre y el miedo; Itaca se desdobla, umbral de partida y destino a la vez, de un viaje de ida y vuelta, siempre repetido, impulsado por un deseo irrealizable y condenado al fracaso; el inmigrante siempre fracasa, piensa Brie, más allá de que tenga algún éxito en la tierra de adopción.

${ }^{10}$ Se incorpora el registro autobiográfico porque Ramaciotti y Achirico son los apellidos reales de los actores. Más adelante, en una especie de parábasis, cada actor abandonará por un momento a sus personajes para presentarse directamente al público con su verdadera identidad (2.5).

11 "Teatro de Los Andes es una muestra viva de la interculturalidad. En su seno conviven argentinos, bolivianos, brasileños, italianos, daneses... y sus montajes siempre están dirigidos a expresar temáticas actuales con la intención de contribuir a mejorar la sociedad." http://www. artezblai.com/artezblai/el-celcit-abre-la-convocatoria-para-participar-en-el-taller-pasantiacon-cesar-brie-y-teatro-de-los-andes-en-el-marco-del-ix-festival-iberoamericano-de-teatrocontemporaneo-de-almagro.html (Consulta: 15-04-2011)

${ }^{12}$ En la grotesca escena las funcionarias les escriben con lápiz labial en el culo el sello de DE POR TA DOS y los despachan como bultos. Estalla el odio y la bronca colectiva por la humillación y la desigualdad: “¿Y la publicidad "más allá de las fronteras”?/ Que se les mueran sus hijos./ Revienten en su veneno./ ¿Y quién les hizo las casas?/ ¿Quién cosechó sus verduras?/ ¿Quién les alza la basura?/ ¿Quién les cuida sus ancianos?/ ¿Quién los coloca en sus tumbas?/ Muéranse todos bastardos./Ignorantes llenos de oro. Ávidos hijos de puta" (2.4).

${ }^{13}$ Atenea reaparece en la escena 5 para disipar las dudas de Ulises sobre la tierra a que ha llegado y que no alcanza a reconocer, Itaca adquiere valor polisémico para designar cualquiera de los países pobres del planeta: "Atenea: -Su nombre es Itaca./ Todos: -Turquía Bolivia Argentina Irán/ Uganda Uruguay Italia Marruecos Méjico Libia” (2.5). 
En la adaptación los dioses pierden la majestad y el poder que los caracterizaba en Homero, tienen escasa participación efectiva en la acción, y son figuras crueles y morbosas que observan desde sus reposeras, tomando sol, el reality show de un mundo depredado por la globalización. Zeus colecciona zapatos de inmigrantes muertos devueltos por la marejada. Hermes se comunica con Calipso por celular, y Ulises ya no es el hijo de Laertes sino Ulises Choque o Ulises Quispe. Polifemo es funcionario de migraciones o jefe de la mara que lo asesina en la frontera mexicana. Caribdis es el mar amenazante y con Escila ladran los perros de la policía y quema el desierto. El grotesco y la pornografía colorean los encuentros de los Ulises americanos con mujeres fatales como Calipso y Circe.

Es en el final donde opera una de las mayores diferencias con el paradigma clásico. Su título, "La guerra civil", se contrapone al episodio "Las paces", escena de reconciliación y olvido que cierra la Odisea homérica. Esta inversión del sentido orienta la recepción de toda la historia. En la Itaca del relato griego, Atenea aparece en un brillante dea ex machina para declarar la amnistía e imponer la pacificación y el olvido. Su intervención vuelve las cosas a un estado de orden y gobernabilidad en beneficio del héroe, su familia y sus aliados. E1 nóstos culmina y se realiza de manera plena y estable. La reescritura de Brie transforma por inversión el modelo canónico de la historia heroica, en la Ítaca latinoamericana del presente, el regreso es doloroso y la paz imposible.

Hechos documentales (4 de julio de 2006 en Portopalo, Sicilia; 1980, Guatemala; agosto de 2011 en el Mediterráneo), identidades reales que dibujan el atlas inmigratorio actual, conviven con episodios y personajes del mito y la ficción en un cruce que otorga al texto una actualidad vertiginosa. Hoy, mayo o agosto de 2011, los periódicos informan de que "centenares de inmigrantes desesperados murieron ahogados en las últimas semanas al intentar cruzar el Mediterráneo a bordo de embarcaciones precarias". En una propuesta escénica profundamente intercultural la matriz mítica se teje con voces del presente y el resultado es un texto complejo que restituye el núcleo metafórico de los antiguos mitos y los reviste de una significación comprometida y actual. La perspectiva se ha invertido, y el destino esperanzador del héroe antiguo deviene un drama colectivo que presenta una visión enteramente pesimista de los efectos reales de la globalización sobre las poblaciones de los países pauperizados del planeta. 


\section{Corpus}

Bérard, V. (ed), (1999) L’Odyssée, Les Belles Lettres, París

Brie, César, (2011) La Odisea, Buenos Aires, CELCIT, No 316, www.celcit. org.ar.

—__ (2000) La Ilíada, Sucre, Teatro de los Andes.

\section{Bibliografía}

Arias, S. (2010), “120 cañahuecas sirven de guía para La Odisea”, en Los Tiempos, 13/05/2010.

Barba, E. (2005), "Fabricantes de sombras (conversación nocturna con Atahualpa del Cioppo)", Cuaderno de Picadero No 7, Instituto Nacional del teatro, 66-70.

Brie, C. (2000), "Preguntas, motivaciones y reflexiones sobre La Ilíada", en La Ilíada, Sucre, Teatro de los Andes.

- (2005), "Risa y llanto en el teatro andino", Cuaderno de Picadero № 7, Instituto Nacional del teatro.

Cilento, L. (2000), “Adaptación de narrativa extranjera: la voz transtextual”, en Dubatti, J. (comp.) Nuevo teatro Nueva crítica, Bs. As., Atuel.

Dubatti, J. (2010), Cartografía teatral. Introducción al teatro comparado, Bs. As., Atuel.

Genette, G. (1989), Figuras III, Barcelona, Lumen.

Lyotard, J-F. (1997), Lecturas de infancia. Joyce. Kafka. Sartre. Valèry. Freud. Bs.As., EUDEBA.

Minchin, Elizabeth (2001), Homer and the Resources of Memory. Some Applications of Cognitive Theory to the Iliad and the Odyssey. USA, Oxford Un. Press.

Pavis (1996), Diccionario de Teatro. Dramaturgia, estética, semiología, Barcelona, Paidós.

Pianacci, Rómulo (2008), Antígona: una tragedia latinoamericana, USA, Gestos.

Zayas de Lima, Perla (2010), Mitos griegos en el discurso teatral argentino, No 11. www.telondefondo.org.ISSN1669 6301 